\title{
Apoptosis in the lungs of pigs infected with porcine reproductive and respiratory syndrome virus and associations with the production of apoptogenic cytokines
}

\author{
Geoffrey LABARQUE, Steven VAN GUCHT, Hans NAUWYNCK, \\ Kristien VAN REETH, Maurice PENSAERT* \\ Laboratory of Virology, Faculty of Veterinary Medicine, Ghent University, Salisburylaan 133, \\ 9820 Merelbeke, Belgium
}

(Received 28 July 2002; accepted 14 November 2002)

\begin{abstract}
Apoptosis was studied in the lungs of pigs during an infection with a European strain of porcine reproductive and respiratory syndrome virus (PRRSV) and it was examined if cytokines were involved in the induction of apoptosis. Twenty-two 4- to 5-week-old gnotobiotic pigs were inoculated intranasally with $10^{6.0}$ TCID $_{50}$ of the Lelystad virus and euthanised between 1 and 52 days post inoculation (PI). The lungs and broncho-alveolar lavage (BAL) cells were assessed both for virus replication and apoptosis; BAL fluids were examined for interleukin (IL)-1, tumour necrosis factor-alpha and IL-10. Double-labellings were conducted to determine the relation between virus replication and apoptosis and to identify the apoptotic cells. Apoptosis occurred in both infected and non-infected cells. The percentages of infected cells, which were apoptotic, ranged between 9 and 39\% in the lungs and between 13 and 30\% in the BAL cells. The majority of apoptotic cells were non-infected. Non-infected apoptotic cells in the lungs were predominantly monocytes/macrophages, whereas those in the broncho-alveolar spaces were predominantly lymphocytes. The peak of apoptosis in the lungs at 14 days PI was preceded by a peak of IL-1 and IL-10 production at 9 days PI, suggesting a possible role of these cytokines in the induction of apoptosis in non-infected interstitial monocytes/macrophages. However, the latter hypothesis was not confirmed in vitro, since blood monocytes or alveolar macrophages did not undergo apoptosis after treatment with recombinant porcine IL-1 or IL-10.
\end{abstract}

pig / lung / porcine reproductive and respiratory syndrome virus / apoptosis / cytokine

\section{INTRODUCTION}

Apoptosis is a physiological mechanism of cell death important for normal cellular turnover that is characterised by internucleosomal DNA degradation and pronounced morphological changes [35]. It also occurs during viral infections and

\footnotetext{
* Correspondence and reprints

Tel.: (32) 926473 65; fax: (32) 926474 95; e-mail: maurice.pensaert@rug.ac.be
} 
there is mounting evidence that it can contribute directly to viral pathogenesis [8].

Recently, it has been demonstrated that the porcine reproductive and respiratory syndrome virus (PRRSV) induces apoptosis in the lungs [7, 17, 24, 27]. On a morphological basis, the apoptotic cells are assumed to be alveolar and pulmonary intravascular macrophages and mononuclear cells in the alveolar septa. Doublelabelling experiments indicate that most apoptotic cells are non-infected [24, 27].

An infection of the lungs with PRRSV has some peculiar cellular features that may be attributed to apoptosis. Firstly, it is characterised by changes in the population of broncho-alveolar monocytes/macrophages, consisting of a reduction of the population of well-differentiated macrophages and an influx of new monocytes [16]. Since apoptosis is an important mechanism of the cell population control in normal tissue homeostasis, it may be involved in the regulation of the number of monocytes/macrophages during this massive influx of new monocytes. Secondly, PRRSV causes only minimal lung inflammation [21] and neutrophil infiltration [16, 31], which also may be attributed to the involvement of apoptotic processes, since apoptotic bodies are phagocytised by resident macrophages without provoking an inflammatory response.

Viral glycoprotein GP5 has been shown to be involved in apoptosis of the PRRSVinfected cell [26]. However, the mechanism of apoptosis in the non-infected cell is unknown. It has been demonstrated that cytokines, such as tumour necrosis factoralpha (TNF- $\alpha)$ [18], interferon-alpha (IFN- $\alpha$ ) [28], interleukin (IL)-1 [6, 11] and interleukin-10 [12,33] can induce apoptosis. A PRRSV infection generally fails to induce substantial amounts of IFN- $\alpha[1$, $30,32]$. This argues against a possible role of this cytokine in PRRSV-induced apoptosis. IL-1, however, is produced at high levels in the lungs of PRRSV-infected pigs from 3 till 10 days after inoculation [31] and a weak TNF- $\alpha$ production has been demonstrated at 12 and 13 days after inoculation [32]. Furthermore, the induction of IL-10 mRNA in alveolar macrophages has been reported in PRRSV-infected pigs [29].

In the present study, the kinetics of apoptosis both in the lungs and bronchoalveolar lavage (BAL) cells was investigated in gnotobiotic pigs upon infection with a European strain of PRRSV, with the purpose of having a better understanding on its potential role in the pathogenesis. Furthermore, it was examined if IL-1, TNF- $\alpha$ and IL-10 may be involved in the induction of apoptosis during a PRRSV infection.

\section{MATERIALS AND METHODS}

\subsection{Virus strain}

A fifth passage on pulmonary alveolar macrophages (PAMs) of the Lelystad strain of PRRSV [34] was used.

\subsection{Pigs and experimental design}

A total of twenty-nine caesareanderived colostrum-deprived (CDCD) pigs were used. They were housed in isolation facilities. Twenty-two pigs were inoculated intranasally at the age of 4 to 5 weeks with $10^{6.0}$ TCID $_{50}$ of the Lelystad virus in $3 \mathrm{~mL}$ phosphate-buffered saline (PBS) (1.5 $\mathrm{mL}$ in each nostril). The remaining seven pigs were left non-inoculated and served as negative controls. One to three of the PRRSV-inoculated pigs were euthanised at $1(n=1), 3(n=2), 5(n=2), 7(n=$ $3), 9(n=3), 14(n=3), 20(n=1), 25(n=$ 2), $30(n=1), 35(n=2), 40(n=1)$ and 52 $(n=1)$ days post inoculation (PI) by intraperitoneal injection with an overdose of barbiturates (Natriumpentobarbital ${ }^{\circledR} 20 \%$, IC KELA, Hoogstraten, Belgium). The control pigs were euthanised at $4(n=2)$, 
$5(n=1), 6(n=1), 8(n=2)$ and $10(n=1)$ weeks of age.

The right lung was used for bronchoalveolar lavage and samples from the left apical, cardiac and diaphragmatic lung lobes were collected for quantification of the infected cells and detection of apoptosis.

\subsection{Collection of samples}

The right lung was lavaged using a previously described method [16]. The BAL fluid was centrifuged $(400 \times \mathrm{g}, 10 \mathrm{~min}$, $4{ }^{\circ} \mathrm{C}$ ) to separate cells and cell-free lavage fluid.

Cell pellets were resuspended in PBS. The total number of BAL cells and their differentiation were determined and the results were published earlier [16]. Cytocentrifuge preparations of BAL cells were made by centrifuging at $140 \times g$ for $5 \mathrm{~min}$. Preparations were fixed in acetone for $20 \mathrm{~min}$ at $-20{ }^{\circ} \mathrm{C}$ for quantification of the infected cells, or in $4 \%$ paraformaldehyde for $10 \mathrm{~min}$ at room temperature for detection of apoptosis.

Cell-free BAL fluids were concentrated 10 times by dialysis against a $20 \% \mathrm{w} / \mathrm{v}$ solution of polyethylene glycol (mol. mass 20000 ), cleared of residual virus by ultra-centrifugation at $100000 \times g$ [31], aliquoted and stored at $-70^{\circ} \mathrm{C}$, until analysis in cytokine bioassays (IL-1, TNF- $\alpha$ ) or cytokine ELISA (IL-10).

Tissue samples from the left lung lobes were embedded in methylcellulose medium and frozen at $-70{ }^{\circ} \mathrm{C}$. Cryostat sections (5 to $8 \mu \mathrm{m}$ ) were made and fixed in acetone for 20 min at $-20{ }^{\circ} \mathrm{C}$ for quantification of infected cells, or in $4 \%$ paraformaldehyde for $10 \mathrm{~min}$ at room temperature for detection of apoptosis.

\subsection{Virological examinations}

PRRSV-infected cells in the lung tissue and BAL cells were quantified using a streptavidin-biotin immunofluorescence technique [16]. In the lung tissue, a distinction was made between single infected cells and viral antigen-positive foci. Viral antigen-positive foci were defined as areas in the lung tissue containing groups of three or more PRRSV-infected cells and cellular debris [16].

\subsection{Detection of apoptosis}

Cytocentrifuge preparations of BAL cells and cryostat sections of lung tissue were processed for enzyme terminal deoxynucleotidyl transferase (TdT)-mediated dUTP nick end labelling (TUNEL) using an In Situ Cell Death Detection Kit, Fluorescein (Roche Diagnostics Belgium, Brussel, Belgium) according to the manufacturer's instructions. Briefly, cytocentrifuge preparations and cryostat sections, fixed in $4 \%$ paraformaldehyde, were treated with Triton X-100 $(0.1 \%)$ at $4{ }^{\circ} \mathrm{C}$ for $2 \mathrm{~min}$. Then, the preparations were subjected to an enzymatic incorporation of digoxygenin-labelled nucleotide with TdT. Finally, the preparations were washed with PBS, mounted in a glycerin-PBS solution $(0.9: 0.1, \mathrm{v} / \mathrm{v})$ with $2.5 \% \quad 1,4-$ diazobicyclo(2.2.2)octane (DABCO) (Janssen Chimica, Beerse, Belgium) and apoptotic cells were detected and enumerated by fluorescence microscopy (Leica DM RBE, Wild Leitz GmbH, Heidelberg, Germany). One cytocentrifuge preparation and three cryostat sections (one of each lung lobe; standard deviation $\leq 500$ cells per $100 \mathrm{~mm}^{2}$ lung tissue) were examined per pig. At least 1000 cells per cytocentrifuge preparation and $20 \mathrm{~mm}^{2}$ lung tissue per cryostat section were analysed.

\subsection{Double-labelling experiments}

Double-labelling experiments were conducted to determine the relation between PRRSV replication and apoptosis. Briefly, cytocentrifuge preparations and cryostat sections, fixed in $4 \%$ paraformaldehyde, were treated with Triton X-100 $(0.1 \%)$ at $4{ }^{\circ} \mathrm{C}$ for $2 \mathrm{~min}$. The preparations 
were first incubated with a pool of monoclonal antibodies (MAb) against the PRRSV nucleocapsid protein (dilution 1/100 of WBE1 and WBE4-6) [9]. Subsequently, the preparations were subjected to an enzymatic incorporation of digoxygenin-labelled nucleotide with $\mathrm{TdT}$ and then incubated with goat anti-mouse TexasRed (dilution 1/100) (Amersham Biosciences, Buckinghamshire, United Kingdom).

Double-labelling experiments were conducted to determine the percentages of apoptotic cells in the subpopulations of $41 \mathrm{D} 3^{+}$cells (monocytes/macrophages), $\mathrm{CD} 2^{+}$cells ( $\mathrm{T}$ lymphocytes and natural killer (NK) cells), $\mathrm{CD}^{+}$cells ( $\mathrm{T}$ helper cells), $\mathrm{CD}^{+}$cells (cytotoxic $\mathrm{T}$ cells and $\mathrm{NK}$ cells) and $\mathrm{wCD}^{+}$cells (B lymphocytes). The percentages in the subpopulation of monocytes/macrophages were determined using MAb 41D3, directed against the putative PRRSV receptor, a $210-\mathrm{kDa}$ protein expressed in macrophages [10]. Briefly, cytocentrifuge preparations of BAL cells and cryostat sections of lung tissue, fixed in $4 \%$ paraformaldehyde, were treated with Triton X-100 $(0.1 \%)$ at $4{ }^{\circ} \mathrm{C}$ for $2 \mathrm{~min}$. The preparations were first incubated with MAb 41D3 (dilution 1/100). Subsequently, the preparations were subjected to an enzymatic incorporation of digoxygenin-labelled nucleotide with TdT and then incubated with goat anti-mouse TexasRed (dilution 1/100) (Amersham Biosciences, Buckinghamshire, United Kingdom). The percentages of apoptotic cells in the subpopulations of $\mathrm{CD} 2^{+}, \mathrm{CD}^{+}$and $\mathrm{CD}^{+}$cells were determined using MAbs MSA4 [19], 74-12-4 [20] and 76-2-11 [36], respectively. The percentages in the subpopulation of B lymphocytes were determined using MAb 76-7-4, directed against wCD1 [4]. Briefly, cytocentrifuge preparations of BAL cells were first incubated with the respective MAbs and subsequently with goat anti-mouse TexasRed (dilution 1/100) (Amersham Biosciences, Buckinghamshire, United Kingdom). Then, the prepa- rations were treated with Triton $\mathrm{X}-100$ $(0.1 \%)$ at $4{ }^{\circ} \mathrm{C}$ for $2 \mathrm{~min}$. Subsequently, the preparations were subjected to an enzymatic incorporation of digoxygeninlabelled nucleotide with TdT.

\subsection{Cytokine bioassays and ELISA}

IL-1 was determined in a proliferation assay using D10(N4)M cells [14, 15]. One unit of IL-1 activity was defined as the reciprocal of the dilution producing $50 \%$ proliferation of D10(N4)M cells. To assign bioactivity to IL-1, monoclonal rat antimouse IL-1 receptor type 1 antibodies (R\&D Systems, Abingdon, United Kingdom) were included in the assay.

TNF- $\alpha$ was determined in a cytotoxicity assay in $\mathrm{PK}(15)$ subclone 15 cells [3]. One unit of TNF- $\alpha$ activity was defined as the reciprocal of the dilution producing $50 \%$ cytotoxicity. Cytotoxic activity was confirmed to be induced by TNF- $\alpha$ by neutralisation of the samples with rabbit antihuman TNF- $\alpha$ (Innogenetics, Zwijnaarde, Belgium).

IL-10 was determined in a commercial ELISA for porcine IL-10 (Biosource Europe, Nivelles, Belgium) according to the manufacturer's instructions.

\subsection{In vitro experiments}

Porcine peripheral blood mononuclear cells (PBMCs) were isolated from heparinised venous blood by FicollPaque $^{\mathrm{TM}}$ Plus (Amersham Biosciences, Buckinghamshire, United Kingdom) density sedimentation. PBMCs were seeded in 24-well cell culture plates (Nunc A/S, Roskilde, Denmark) at a concentration of $10^{7}$ cells per well. Monocytes were isolated from PBMCs by adherence on a culture flask for $2 \mathrm{~h}$ at $37{ }^{\circ} \mathrm{C}, 5 \% \mathrm{CO}_{2}$. Nonadherent cells were removed by washing and the adherent cells were cultured at $37{ }^{\circ} \mathrm{C}$ overnight. After an additional washing, the final adherent population was used as the source of blood monocytes. Porcine 
alveolar macrophages were obtained by means of a broncho-alveolar lavage and seeded in 24-well cell culture plates (Nunc A/S, Roskilde, Denmark) at a concentration of $10^{6}$ cells per well. One day after seeding, blood monocytes and alveolar macrophages were treated with recombinant porcine IL-1 $\beta$ (gift from A. Billiau, Leuven, Belgium) at a concentration of $200 \mathrm{U} / \mathrm{mL}\left(75 \times 10^{3} \mathrm{ng} / \mathrm{mL}\right)$ or with recombinant porcine IL-10 (Biosource Europe, Nivelles, Belgium) at concentrations of 1,10 , or $100 \mathrm{ng} / \mathrm{mL}$. Functional activity of both recombinant porcine IL- $1 \beta$ and recombinant porcine IL-10 had been proven in a proliferation assay using D10(N4)M cells $[14,15]$ and the mouse mast cell line D36 [23], respectively. Untreated cells were included as controls. Morphological analysis of the cells was performed daily with a contrast-phase Olympus microscope (Hamburg, Germany). The cells were harvested at $96 \mathrm{~h}$ after treatment. Cytocentrifuge preparations were made, fixed in $4 \%$ paraformaldehyde for $10 \mathrm{~min}$ at room temperature and processed for enzyme terminal deoxynucleotidyl transferase (TdT)-mediated dUTP nick end labelling (TUNEL) using an In Situ Cell Death Detection Kit, Fluorescein (Roche Diagnostics Belgium, Brussel, Belgium) according to the manufacturer's instructions. Apoptotic cells were detected and enumerated by fluorescence microscopy (Leica DM RBE, Wild Leitz GmbH, Heidelberg, Germany)

\section{RESULTS}

\subsection{Quantification of PRRSV-infected and apoptotic cells in lung tissue} (Fig. 1)

PRRSV-infected cells were observed from 3 until 25 days PI with a maximal number of 61 cells/100 $\mathrm{mm}^{2}$ at 7 days PI. Viral antigen-positive foci were observed between 3 and 14 days PI with a maximal number of 37 foci/ $100 \mathrm{~mm}^{2}$ at 9 days PI (not shown).

Apoptotic cells were detected in the lung tissue of both non- and PRRSV-inoculated pigs. In the seven non-inoculated control pigs, the mean number was $1350 \pm$ 263 cells $/ 100 \mathrm{~mm}^{2}$. In PRRSV-inoculated pigs, mean numbers were similar to those of non-inoculated pigs until 3 days PI. The mean numbers increased significantly from $1800 \pm 424$ cells $/ 100 \mathrm{~mm}^{2}$ at 3 days PI to a level of 4800-4967 \pm 1054 1097 cells $/ 100 \mathrm{~mm}^{2}$ at $7-9$ days PI $(P<$ 0.05; one-way ANOVA) and then peaked at $8330 \pm 1070$ cells $/ 100 \mathrm{~mm}^{2}$ at 14 days PI. From 20 days PI, the mean numbers returned to those of non-inoculated pigs.

Double-labellings revealed that within the population of infected cells, apoptosis was detected from 5 until 25 days PI with percentages ranging between 9 and 39\%. The majority of apoptotic cells (> 99\%) were non-infected. There was a spatial correlation between the sites of PRRSV replication and apoptosis. Non-infected apoptotic cells were more abundant in viral antigen-positive foci and they were frequently seen in close proximity to infected cells (not shown).

Double-labelling experiments with $\mathrm{MAb}$ $41 \mathrm{D} 3$ revealed that 76 to $88 \%$ of the apoptotic cells were of the monocyte/macrophage lineage.

\subsection{Quantification of PRRSV-infected and apoptotic cells in the broncho- alveolar spaces (Fig. 2)}

PRRSV-infected cells were first observed at 1 day PI $\left(3 \times 10^{6}\right.$ cells $)$, increased to a maximum of $15 \times 10^{6}$ cells at 9 days PI, decreased to $3 \times 10^{6}$ cells at 14 days PI and remained at levels of 0.5 $1 \times 10^{6}$ cells until 40 days PI.

Apoptotic cells were detected in the broncho-alveolar spaces of both non- and PRRSV-inoculated pigs. In the seven noninoculated control pigs, the mean number was $5.3 \pm 1.8 \times 10^{6}$. In PRRSV-inoculated 


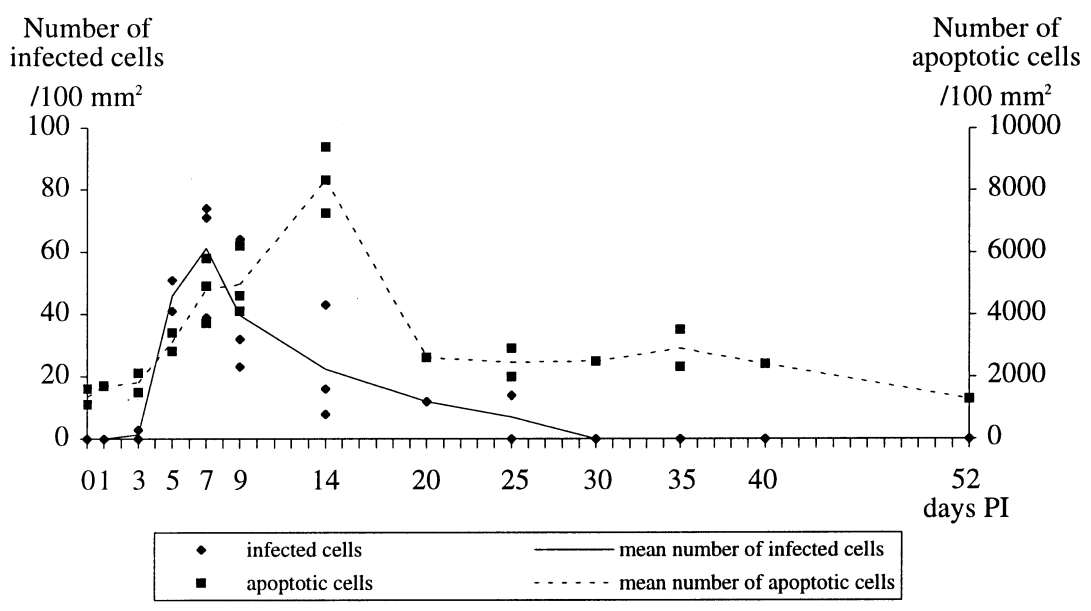

Figure 1. Quantification of infected and apoptotic cells in lung tissue $\left(/ 100 \mathrm{~mm}^{2}\right)$ throughout a PRRSV infection.

Values at day 0 represent the numbers of infected and apoptotic cells of two non-inoculated control pigs euthanised at 4 weeks of age.

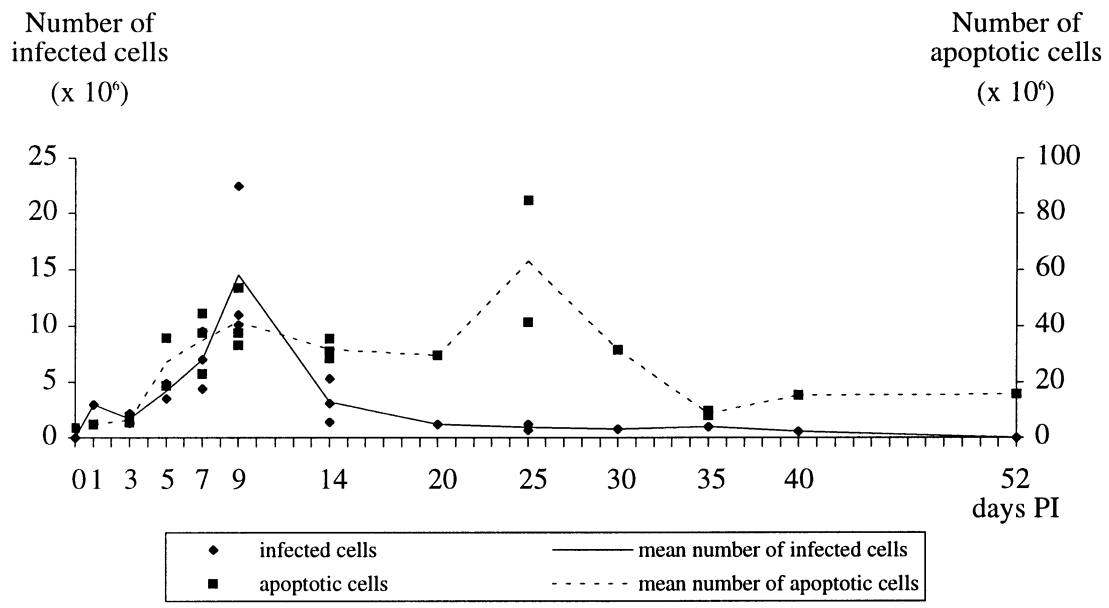

Figure 2. Quantification of infected and apoptotic broncho-alveolar lavage (BAL) cells $\left(\times 10^{6}\right)$ throughout a PRRSV infection.

Values at day 0 represent the numbers of infected and apoptotic cells of two non-inoculated control pigs euthanised at 4 weeks of age.

pigs, the mean numbers were similar to those of non-inoculated pigs until 3 days PI. The mean numbers increased significantly from $6.6 \pm 1.7 \times 10^{6}$ at 3 days PI to a first maximum of $41.4 \pm 10.8 \times 10^{6}$ at
9 days PI $(P<0.05$; one-way ANOVA $)$, then remained at the same level until 20 days PI and reached a second maximum of $63.0 \pm 31.0 \times 10^{6}$ at 25 days PI. From 35 days PI onwards, the mean numbers 

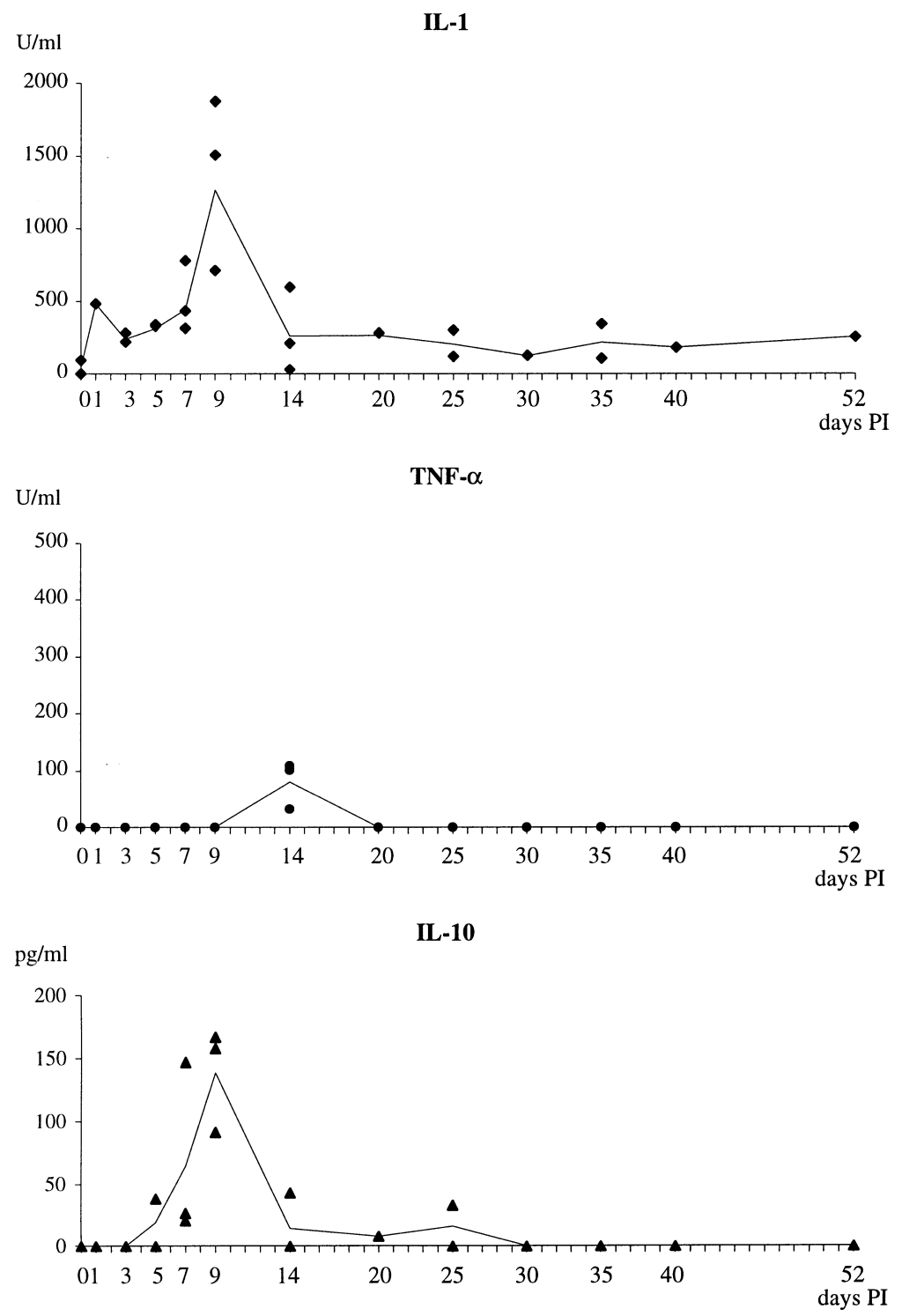

Figure 3. Interleukin-1 (IL-1), tumour necrosis factor-alpha (TNF- $\alpha$ ) and interleukin-10 (IL-10) levels in broncho-alveolar lavage (BAL) fluids throughout a PRRSV infection. The dots represent individual cytokine levels; the lines represent means at each time point.

Values at day 0 represent the cytokine levels of two non-inoculated control pigs euthanised at 4 weeks of age. 
of apoptotic cells of PRRSV-inoculated pigs were not different from those of noninoculated pigs.

Double-labellings revealed that within the population of infected BAL cells, apoptosis was detected until 25 days PI with percentages ranging between 13 and $30 \%$ and that the majority of apoptotic cells (>99\%) were non-infected.

Mean percentages of apoptotic cells remained constant in the total population of BAL cells and in the subpopulation of monocytes/macrophages (41D ${ }^{+}$cells). In the subpopulation of $\mathrm{T}$ lymphocytes and NK cells, mean percentages reached a maximum at $7\left(\mathrm{CD}^{+}\right.$cells) or 9 days PI $\left(\mathrm{CD} 2^{+}\right.$and $\mathrm{CD}^{+}$cells), sharply decreased thereafter and then remained at constant levels until 52 days PI. In the subpopulation of B lymphocytes ( $\mathrm{wCD} 1^{+}$cells), apoptotic cells peaked at 5 to 9 days PI and decreased sharply thereafter.

\subsection{IL-1, TNF- $\alpha$ and IL-10 production in BAL fluids (Fig. 3)}

A low level of IL-1 $(71 \mathrm{U} / \mathrm{mL})$ was found in one out of the seven non-inoculated pigs. The other control pigs had no detectable amounts of IL-1. All PRRSV-inoculated pigs had detectable IL-1 production. The pig euthanised at 1 day PI had an IL-1 titre of $483 \mathrm{U} / \mathrm{mL}$. Mean IL-1 titres increased from $240 \mathrm{U} / \mathrm{mL}$ at 3 days PI to a maximum of $1265 \mathrm{U} / \mathrm{mL}$ at 9 days PI, decreased to $263 \mathrm{U} / \mathrm{mL}$ at 14 days PI and remained at levels of 121-267 U/mL until 52 days PI.

All non-inoculated control pigs were negative for TNF- $\alpha$. After PRRSV inoculation, TNF- $\alpha$ was only found in the three pigs euthanised at 14 days PI, at low levels (32-109 U/mL).

All non-inoculated control pigs were negative for IL-10. After PRRSV inoculation, IL-10 was found starting from 5 days PI (19 pg/mL). Mean IL-10 levels reached a maximum of $139 \mathrm{pg} / \mathrm{mL}$ at 9 days PI, decreased to $14 \mathrm{pg} / \mathrm{mL}$ at 14 days PI and remained at levels of $8-17 \mathrm{pg} / \mathrm{mL}$ until 25 days PI.

\subsection{Quantification of apoptotic cells after in vitro treatment with recombinant porcine IL-1 $\beta$ or IL-10}

No morphological features of apoptosis, such as cell shrinkage and cytoplasm hypervacuolisation, were observed in the monocyte and macrophage cultures throughout the experiment. Four days after treatment with recombinant porcine IL-1 $\beta$ or IL-10, the relative numbers of apoptotic blood monocytes and alveolar macrophages did not differ from those of untreated cells. Only $2.0 \%$ of the untreated blood monocytes and $6.5 \%$ of the untreated alveolar macrophages showed apoptosis. After treatment with recombinant porcine IL-1 $\beta$, percentages of apoptotic blood monocytes and alveolar macrophages were 2.4 and $5.3 \%$, respectively. Similar results were obtained after treatment with the different concentrations of recombinant porcine IL-10. Between 2.5 and $4.0 \%$ of blood monocytes and between 5.1 and $6.9 \%$ of alveolar macrophages were apoptotic.

\section{DISCUSSION}

The present study showed a clear relation between the peak of virus replication and the onset of apoptosis in the lungs of PRRSV-infected pigs. Apoptosis occurred both in virus-infected and in non-infected cells. Most apoptotic cells were noninfected, which is in agreement with previous studies [7, 24, 27].

The pattern of apoptosis in the noninfected cells was different in lung tissue compared to broncho-alveolar spaces. In lung tissue, apoptosis peaked at 14 days PI and occurred predominantly in monocytes/ macrophages. Earlier studies showed that a PRRSV infection induces a two- to 
fivefold increase of the number of broncho-alveolar monocytes/macrophages [16]. Since apoptosis is a homeostatic process that serves primarily to eliminate redundant cells during normal development and to eradicate defective cells, apoptosis of interstitial monocytes/macrophages throughout a PRRSV infection may be a mechanism of cell population control. However, the process of apoptosis is apparently not sufficient to completely control the massive influx of new monocytes since abundant monocytes/macrophages cross the interstitium towards the broncho-alveolar spaces [16].

The mechanism of apoptosis in noninfected interstitial monocytes/macrophages is not known. It has been suggested that TNF- $\alpha$ may be responsible for the induction of apoptosis in these cells [7]. However, in the present study only a very weak TNF- $\alpha$ production was detected at 14 days PI. Our in vivo data suggest that IL-1 and IL-10 could be involved in the induction of apoptosis in non-infected interstitial monocytes/macrophages. IL-1 and IL-10 levels peaked at 9 days PI and coincided with a significant increase in apoptotic cell numbers. Even though, both cytokines probably do not play a role in the induction of apoptosis in non-infected interstitial monocytes/macrophages, since we failed to induce apoptosis in blood monocytes or alveolar macrophages in vitro with recombinant porcine IL- $1 \beta$ or IL-10. Using similar in vitro experiments, both cytokines were shown to induce apoptosis in human cells. IL-1 $\beta$ was shown to induce apoptosis in a glioblastoma-derived human cell line when concentrations between 1 and $200 \mathrm{U} / \mathrm{mL}$ were used [6]. Similarly, human monocytes/macrophages underwent apoptosis following treatment with $10 \mathrm{ng} / \mathrm{mL}$ of IL-10 [33]. Thus, the exact mechanism by which PRRSV triggers apoptosis in non-infected interstitial monocytes/macrophages is still under debate. In addition to cytokines, macrophages may produce a lot of other apoptogenic mediators, such as nitric oxide and reactive oxygen species, and any or all of these mediators may contribute to the induction of apoptosis in non-infected monocytes/macrophages. Besides these apoptogenic mediators, viral glycoprotein GP5, incorporated in cellular debris, may also be responsible for the induction of apoptosis in non-infected cells. This glycoprotein has clearly been shown to be involved in the induction of apoptosis [26]. Perhaps, induction of apoptosis can also be alternatively accomplished by attachment of whole virus particles to the cell without penetration and ensuing viral infection. Furthermore, the phagocytic clearance of cellular debris in viral antigen-positive foci by monocytes/macrophages may also be responsible for the apoptosis of noninfected cells. It has been demonstrated that phagocytosis triggers macrophage release of the Fas ligand and induces apoptosis in bystander leukocytes [5]. Since monocytes/macrophages themselves express Fas, cross-linking of Fas with the soluble Fas ligand may indeed induce apoptosis in non-infected bystander monocytes/macrophages. Both GP5 and phagocytosis may explain why the highest number of apoptotic cells was found in the proximity of viral antigen-positive foci. Furthermore, in these regions, apoptotic cells may have been wrongly defined as non-infected, since some of these cells may have been in the early stage of the PRRSV replication cycle and thus not yet expressing viral antigens.

In the broncho-alveolar spaces, two peaks of apoptosis were detected. The first peak at 9 days PI involved mainly lymphocytes. Both $\mathrm{T}$ helper cells $\left(\mathrm{CD} 2^{+} \mathrm{CD} 4^{+}\right.$ $\mathrm{CD}^{-}$), cytotoxic $\mathrm{T}$ cells and $\mathrm{NK}$ cells $\left(\mathrm{CD} 2^{+} \mathrm{CD} 4^{-} \mathrm{CD} 8^{+}\right)$, and $\mathrm{B}$ cells $\left(\mathrm{wCD}^{+}\right)$ underwent apoptosis. The percentage of apoptotic cells in $\mathrm{T}$ lymphocytes was the highest at the peak of virus replication in BAL cells. This suggests that the PRRSV infection induces apoptosis in bronchoalveolar T lymphocytes and NK cells. This is not surprising since $\mathrm{T}$ lymphocytes, activated during the antiviral immune 
response, are predisposed to undergo apoptosis [22]. The second peak of apoptosis at 25 days PI can be explained by the fact that the total BAL cell numbers were the highest at that time point, as demonstrated in a previous study [16].

Apoptosis was detected in virusinfected macrophages during the persistent stage of the PRRSV infection. Previous studies have demonstrated that the appearance of a PRRSV-specific immunity causes a significant decrease in the number of viral antigen-positive cells starting at 9 days PI. Nevertheless, a low number of single viral antigen-positive cells persists in the lungs for several weeks [16]. Why these single viral antigen-positive cells are able to persist despite the presence of immunity is not known, but may be in part attributable to the apoptotic process in infected cells. It has been suggested that apoptosis of virus-infected cells may represent a very efficient mechanism for viruses to escape from humoral immunity. The progeny virus which is present in apoptotic bodies can be taken up by neighbouring macrophages while protected from antibodies. This type of immune-evasion has already been described for the human immunodeficiency virus type 1 [25], herpes simplex virus type 2 [2] and EpsteinBarr virus [13].

Taken together, apoptosis seems to have a homeostatic effect on the number of monocytes/macrophages during the massive influx of new monocytes in the lungs of PRRSV-infected pigs and may explain why a low number of single viral antigenpositive cells persists in the lungs for several weeks despite the presence of immunity.

\section{ACKNOWLEDGEMENTS}

The authors would like to thank Fernand De Backer, Chris Bracke, Inge Pareyn and Lieve Sys for excellent technical assistance. The authors would also like to thank Dr. T. Drew for his kind gift of the monoclonal antibodies
WBE1 and WBE4-6 and Prof. Billiau for the supply of the recombinant porcine IL-1 $\beta$. Geoffrey Labarque was supported by Grant 011D5898 from the Research Council of the Ghent University.

\section{REFERENCES}

[1] Albina E., Carrat C., Charley B., Interferonalpha response to swine arterivirus (PoAV), the porcine reproductive and respiratory syndrome virus, J. Interferon Cytokine Res. 18 (1998) 485-490.

[2] Asano S., Honda T., Goshima F., Watanabe D., Miyake Y., Sugiura Y., Nishiyama Y., US3 protein kinase of herpes simplex virus type 2 plays a role in protecting corneal epithelial cells from apoptosis in infected mice, J. Gen. Virol. 80 (1999) 51-56.

[3] Bertoni G., Kuhnert P., Peterhans E., Pauli U., Improved bioassay for the detection of porcine tumour necrosis factor using a homologous cell line: PK(15), J. Immunol. Methods 160 (1993) 267-271.

[4] Boersma W.J.A., Zwart R.J., Sinkora J., Rehakova Z., Haverson K., Bianchi A.T.J., Summary of workshop findings for porcine B-cell markers, Vet. Immunol. Immunopathol. 80 (2001) 63-78.

[5] Brown S.B., Savill J., Phagocytosis triggers macrophage release of Fas ligand and induces apoptosis of bystander leukocytes, J. Immunol. 162 (1999) 480-485.

[6] Castigli E., Arcuri C., Giovagnoli L., Luciani R., Secca T., Gianfranceschi G.L., Bocchini V., Interleukin-1 beta induces apoptosis in GL15 glioblastoma-derived human cell line, Am. J. Physiol.-Cell Physiol. 279 (2000) 2043-2049.

[7] Choi C., Chae C., Expression of tumour necrosis factor- $\alpha$ is associated with apoptosis in lungs of pigs experimentally infected with porcine reproductive and respiratory syndrome virus, Res. Vet. Sci. 72 (2002) 45-49.

[8] Collins M., Potential roles of apoptosis in viral pathogenesis, Am. J. Respir. Crit. Care Med. 152 (1995) S20-S24.

[9] Drew T.W., Meulenberg J.J.M., Sands J.J., Paton D.J., Production, characterization and reactivity of monoclonal antibodies to porcine reproductive and respiratory syndrome virus, J. Gen. Virol. 76 (1995) 1361-1369.

[10] Duan X., Nauwynck H.J., Favoreel H.W., Pensaert M.B., Porcine reproductive and respiratory syndrome virus infection of alveolar macrophages can be blocked by monoclonal 
antibodies against cell surface antigens, Adv. Exp. Med. Biol. 440 (1998) 81-88.

[11] Dunger A., Augstein P., Schmidt S., Fischer U., Identification of interleukin-1 induced apoptosis in rat islets using in situ specific labeling of fragmented DNA, J. Autoimmun. 9 (1996) 309-313.

[12] Estaquier J., Ameisen J.C., A role for T-helper type- 1 and type- 2 cytokines in the regulation of human monocyte apoptosis, Blood 90 (1997) 1618-1625.

[13] Holmgren L., Szeles A., Rajnavolgyi E., Folkman J., Klein G., Ernberg I., Falk K.I., Horizontal transfer of DNA by the uptake of apoptotic bodies, Blood 93 (1999) 39563963.

[14] Hopkins S.J., Humphreys M., Simple, sensitive and specific bioassay of interleukin-1, J. Immunol. Methods 120 (1989) 271-276.

[15] Hopkins S.J., Humphreys M., Bioassay of interleukin-1 in serum and plasma following removal of inhibitory activity with polyethylene glycol, J. Immunol. Methods 133 (1990) 127-131.

[16] Labarque G.G., Nauwynck H.J., Van Reeth K., Pensaert M.B., Effect of cellular changes and onset of humoral immunity on the replication of porcine reproductive and respiratory syndrome virus in the lungs of pigs, J. Gen. Virol. 81 (2000) 1327-1334.

[17] Labarque G.G., Nauwynck H.J., Van Reeth K., Pensaert M.B., Apoptosis in the lungs of pigs during an infection with a European strain of porcine reproductive and respiratory syndrome virus, Adv. Exp. Med. Biol. 494 (2001) 691-697.

[18] Larrick J.W., Wright S.C., Cytotoxic mechanism of tumour necrosis factor- $\alpha$, FASEB J. 4 (1990) 3215-3223.

[19] Pescovitz M.D., Aasted B., Canals A., Dominguez J., Vizcaino J.S., Pospisil R., Sinkora J., Salmon H., Valpotic I., Davis W.C., Arn S., Sachs D.H., Lunney J.K., Zuckerman F., Weiland E., Saalmuller A., Analysis of monoclonal antibodies reactive with the porcine CD2 antigen, Vet. Immunol. Immunopathol. 43 (1994) 229-232.

[20] Pescovitz M.D., Aasted B., Canals A., Dominguez J., Vizcaino J.S., Pospisil R., Trebichavsky I., Salmon H., Valpotic I., Davis W.C., Arn S., Sachs D.H., Lunney J.K., Zuckerman F., Weiland E., Saalmuller A., Analysis of monoclonal antibodies reactive with the porcine CD4 antigen, Vet. Immunol. Immunopathol. 43 (1994) 233236.
[21] Pol J.M.A., Van Dijk J.E., Wensvoort G., Terpstra C., Pathological, ultrastructural, and immunohistochemical changes caused by Lelystad virus in experimentally induced infections of Mystery Swine disease (Synonym-Porcine Epidemic Abortion and Respiratory Syndrome (PEARS)), Vet. Q. 13 (1991) 137-143.

[22] Razvi E.S., Welsh R.M., Apoptosis in viral infections, Adv. Virus Res. 45 (1995) 1-60.

[23] Schlaak J.F., Schmitt E., Huls C., Meyer zum Buschenfelde K.H., Fleischer B., A sensitive and specific bioassay for the detection of human interleukin-10, J. Immunol. Methods 168 (1994) 49-54.

[24] Sirinarumitr T., Zhang Y., Kluge J.P., Halbur P.G., Paul P.S., A pneumo-virulent United States isolate of porcine reproductive and respiratory syndrome virus induces apoptosis in bystander cells both in vitro and in vivo, $\mathrm{J}$. Gen. Virol. 79 (1998) 2989-2995.

[25] Spetz A.L., Patterson B.K., Lore K., Andersson J., Holmgren L., Functional gene transfer of HIV DNA by an HIV receptorindependent mechanism, J. Immunol. 163 (1999) 736-742.

[26] Suárez P., Diaz-Guerra M., Prieto C., Esteban M., Castro J.M., Nieto A., Ortin J., Open reading frame 5 of porcine reproductive and respiratory syndrome virus as a cause of virus-induced apoptosis, J. Virol. 70 (1996) 2876-2882.

[27] Sur J.-H., Doster A.R., Osorio F.A., Apoptosis induced in vivo during acute infection by porcine reproductive and respiratory syndrome virus, Vet. Pathol. 35 (1998) 506-514.

[28] Suzuki S., Takagi S., Miyata M., The induction of apoptosis by interferon-alpha on myeloma and CML cell lines, Exp. Hematol. 24 (1996) 319.

[29] Thanawongnuwech R., Thacker B., Thacker E., Cytokine profiles following $M$. hyopneumoniae and PRRSV co-infection using semiquantitative RT-PCR measurement, Proceedings of the 16th International Pig Veterinary Society Congress, 2000, p. 173.

[30] Trebichavsky I., Valicek L., Immunoreactivity of interleukin-8 and absence of interferonalpha in porcine bronchoalveolar lavage cells infected with PRRS virus, Vet. Med.-Czech. 43 (1998) 7-10.

[31] Van Reeth K., Labarque G., Nauwynck H., Pensaert M., Differential production of proinflammatory cytokines in the pig lung during different respiratory virus infections: correlations with pathogenicity, Res. Vet. Sci. 67 (1999) 47-52. 
[32] Van Reeth K., Nauwynck H., Proinflammatory cytokines and viral respiratory disease in pigs, Vet. Res. 31 (2000) 187-213.

[33] Wang Z.-Q., Bapat A.S., Rayanade R.J., Dagtas A.S., Hoffmann M.K., Interleukin-10 induces macrophage apoptosis and expression of CD16 (FcrRIII) whose engagement blocks the cell death programme and facilitates differentiation, Immunology 102 (2001) 331-337.

[34] Wensvoort G., Terpstra C., Pol J.M.A., ter Laak E.A., Bloemraad M., de Kluyver E.P., Kragten C., van Buiten L., den Besten A., Wagenaar F., Broekhuijsen J.M., Moonen P.L.J.M., Zetstra T., de Boer E.A., Tibben H.J., de Jong M.F., van 't Veld P., Groenland
G.J.R., van Gennep J.A., Voets M.T., Verheijden J.H.M., Braamskamp J., Mystery swine disease in the Netherlands: the isolation of Lelystad virus, Vet. Q. 13 (1991) 121-130.

[35] Wyllie A.H., Kerr J.F.R., Currie A.R., Cell Death: the significance of apoptosis, Int. Rev. Cytol. 68 (1980) 251-306.

[36] Zuckermann F.A., Pescovitz M.D., Aasted B., Dominguez J., Trebichavsky I., Novikov B., Valpotic I., Nielsen J., Arn S., Sachs D.H., Lunney J.K., Boyd P., Walker J., Lee R., Davis W.C., Barbosa I.R., Saalmuller A., Report on the analyses of $\mathrm{mAb}$ reactive with porcine CD8 for the second international swine CD workshop, Vet. Immunol. Immunopathol. 60 (1998) 291-303. 